\title{
Fatigue Analysis of AISI 8620 carburized steels using SEM
}

Marco Antonio Doñu Ruiz ${ }^{1}$, Noé López Perrusquia ${ }^{1}$, Pablo Cruz Carmona ${ }^{2}$ and Victor Jorge Cortéz Suarez $^{2}$

${ }^{1}$ Universidad Politecnica del Valle de México, Tultitlan, Distrito Federal, Mexico, ${ }^{2}$ Universidad Autónoma Metropolitana Azcapotzalco., Distrito Federal, Mexico

AISI 8620 steel is used in machine elements, which are subjected to variable loads. The behavior of the materials under this type of load is different from that under static loads; while a part supports a large static load, it can failure with a much smaller load if it is repeated a large number of times [1]. Due to this, it is possible to increase its service life using thermochemical and heat treatment techniques [2]. AISI 8620 steel specimens were used as shown in Figure 1a. The thermochemical carburizing treatment was carried out at $950^{\circ} \mathrm{C}$ for $5 \mathrm{~h}$, the composition of the carburizing (C) mixture with $10 \%$ BaCo3+30\% graphite+60\% carbon. Then, the carburized specimens were subjected to quenching and tempering (QT) at $950^{\circ} \mathrm{C}$ for $1 \mathrm{~h}$ and $316^{\circ} \mathrm{C}$ for $1 \mathrm{~h}$, respectively. Both processes were carried out in a conventional muffle. Low cycle fatigue tests on 8620 steel with C+QT were performed with an Instron model 8502 Universal Mechanical Testing Machine at $0.25 \mathrm{~mm}, 0.5 \mathrm{~mm}$, and $1.00 \mathrm{~mm}$ cycle amplitude to failure conditions. After the surface fracture, fracture images were analyzed by scanning electron microscopy using a JEOL JSM-6010L. The received specimen has a microstructure with ferritic matrix and pearlite islands as shown in Figure 1b, after (C+QT) a carburized layer with a thickness of $823 \mu \mathrm{m}$ was observed with annealed martensite Figure 1c. On the other hand, Figure 2a shows the maximum stresses (S) and the number of cycles $(\mathrm{N})$ obtained in the three cycle amplitude conditions of $0.25,0.5$ and $1 \mathrm{~mm}$ as a result of a decrease of 2186, 1531 and 423 cycles. The trend equation of the S-N curves was obtained to estimate the mechanical behavior of AISI 8620 steel with C+QT exposed to low cycle fatigue. Figure $2 b$ to $d$, the fractography is observed in the $5 \mathrm{~mm}$ amplitude condition. Figure $2 \mathrm{~b}$ shows that the crack pattern is river. Zone A represents the vicinity of the low-cycle fatigue crack nucleation, where the carburized zone is located. Zone B is a crack propagation zone where the carburized zone is located and the predominant fracture is intergranular (Figure 2c). In the crack propagation zone, in this section, it is observed that the transgranular fracture predominates since there is little cleavage because pores and ductile tearing are observed in Figure 2d.Thermal and thermochemical treatments to AISI 8620 steel showed the change in performance under fatigue conditions, which describe the cycle displacement amplitude increases, the number of cycles supported by the steel decreases. 


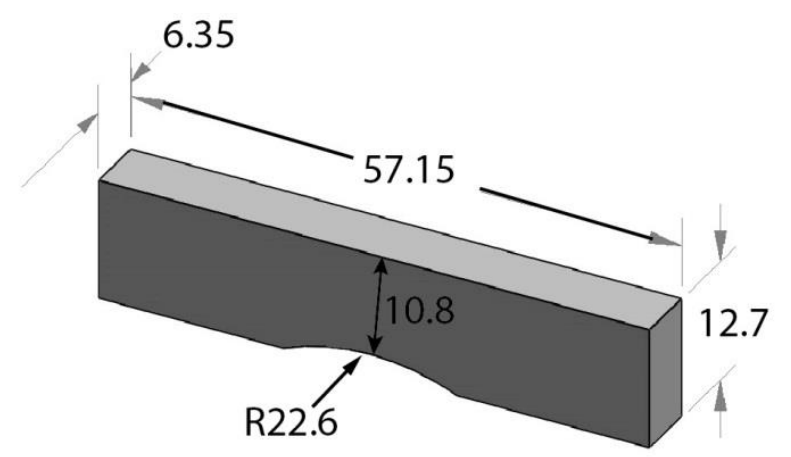

Act: $\mathrm{mm}$

(a)

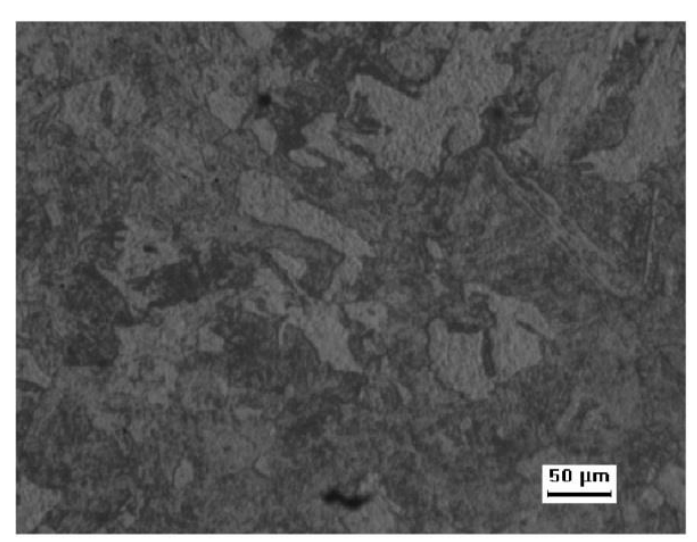

(b)

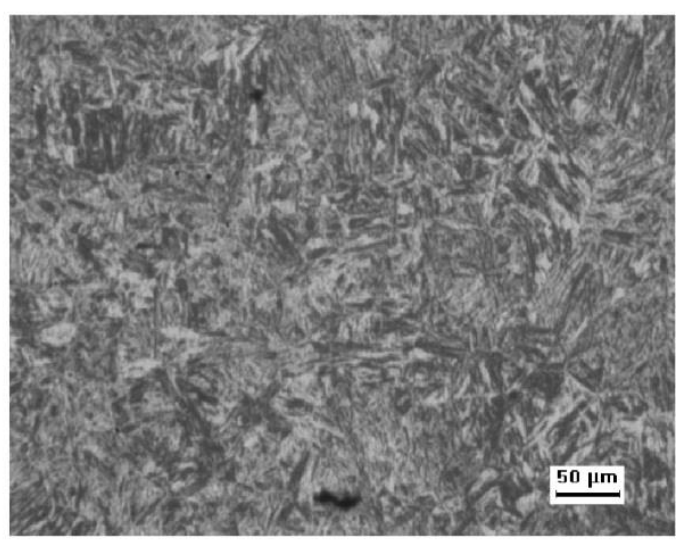

(c)

Figure 1. Specimen condition a) Fatigue test specimen by bending test b) microstructure as received, and c) AISI 8620 steel with C+QT. 


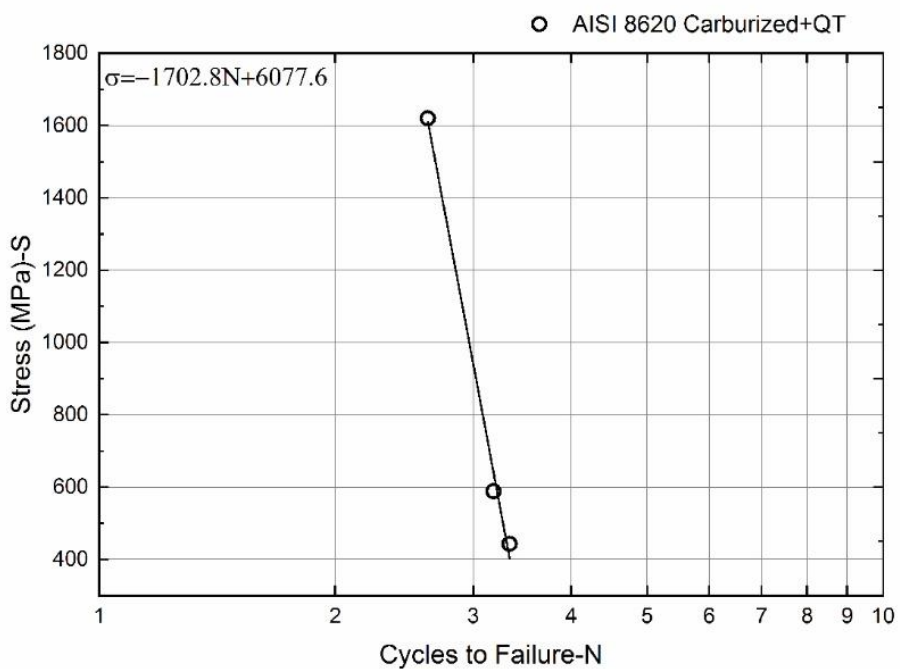

(a)

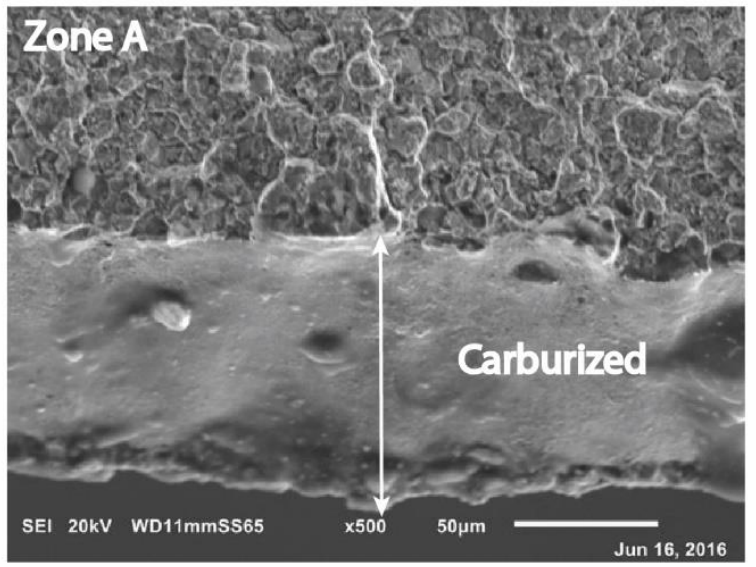

(c)

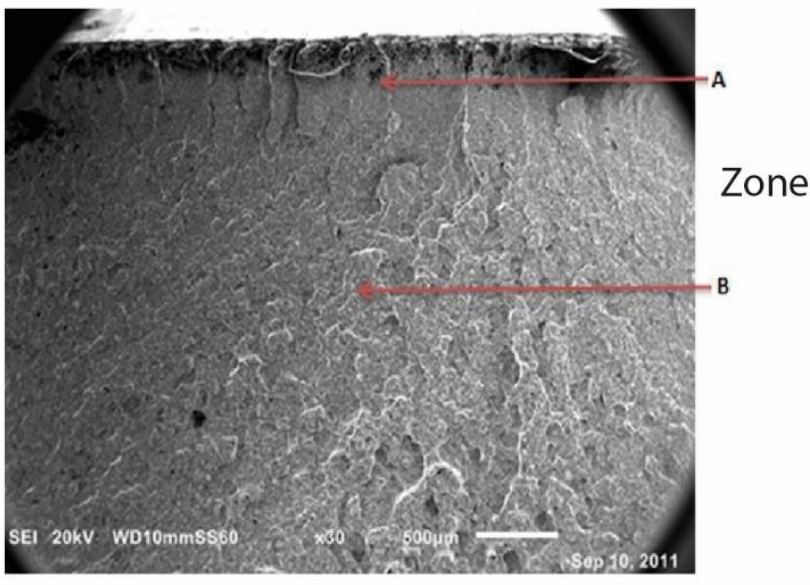

(b)

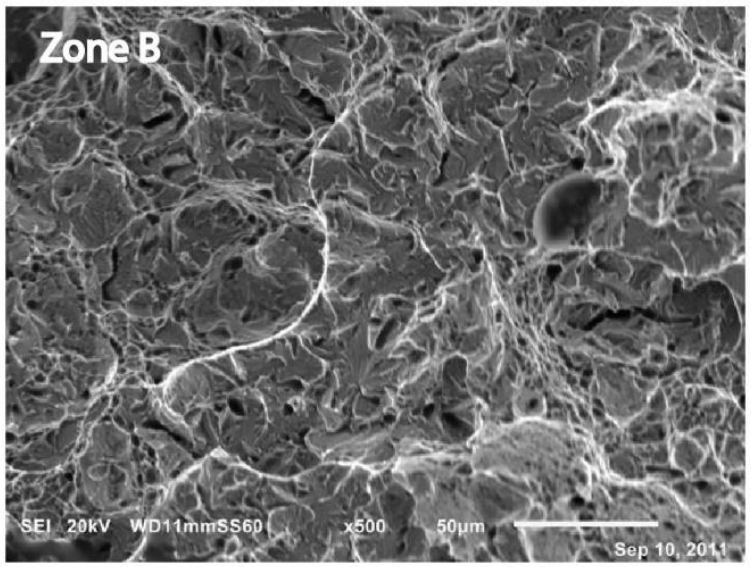

(d)

Figure 2. Fatigue test a) Fatigue curve on AISI 8620 steel with C+QT, and b) SEM fractography of amplitude $0.5 \mathrm{~mm} \mathrm{c}$ ), zone $\mathrm{A}$, and d) zone $\mathrm{B}$.

\section{References}

[1] O. Asi, Fatigue failure of a helical gear in a gearbox, Eng. Fail. Anal. (2006). doi:10.1016/j.engfailanal.2005.07.020.

[2] T. Materials, I. Company, Vol 04,Heat Treating.pdf, (n.d.) 